\title{
Social preferences for the design of biodiversity offsets for shorebirds in Australia
}

\author{
Abbie A Rogers ${ }^{a, b}$ and Michael P Burton ${ }^{a, b}$ \\ ${ }^{a}$ Centre for Environmental Economics and Policy, M089, \\ School of Agricultural and Resource Economics, \\ The University of Western Australia, \\ 35 Stirling Hwy, CRAWLEY, WA 6009 \\ Australia. \\ ${ }^{\text {b}}$ Oceans Institute, The University of Western Australia \\ Corresponding author contact details: \\ P: $+61(0) 864885506$ \\ E: abbie.rogers@uwa.edu.au
}

CITATION: Rogers, A.A. and Burton, M.P. 2017. Social preferences for the design of biodiversity offsets for shorebirds in Australia. Conservation Biology, 31(4): 828-836.

Keywords: biodiversity offsets; choice experiment; community acceptance; offset policy; nonmarket valuation; migratory shorebirds.

Acknowledgements: The Australian Government's National Environmental Research Program Marine Biodiversity Hub and the Australian Research Council's Centre of Excellence for Environmental Decisions are acknowledged for their funding and support.

\begin{abstract}
Understanding the social acceptability of biodiversity offsets is important in order to properly design offset policy. This study used a discrete choice experiment to quantify preferences of the Australian people for a migratory shorebird offset, in the context of an oil and gas development. We used both current and prospective offset policy characteristics, with a view to informing future policy design of the social dimensions related to offset acceptability. We found that the practice of offsetting was accepted by the community as a means to allow economic development. Substituting protection of a species impacted by the development for a more endangered species was a desirable policy characteristic, as was having the offset implemented by a third party or the government, rather than the company responsible for the development. Direct offset activities were preferred over indirect, and there was a strong aversion to locating the offset at a site other than where the impact occurred. The rate at which positive and negative characteristics can be traded off is identified.
\end{abstract}

\section{Introduction}

Biodiversity offsets can compensate for unavoidable environmental impacts resulting from development. The potential for offsets to allow project specific investments to proceed while accounting for environmental damage has drawn international interest from government and nongovernment agencies, and development companies. Offset policies are being implemented by governments worldwide to formalize the appropriate design of offsets (Mckenney \& Kiesecker 2010). While the objectives of these policies are often similar, typically centred on the concept of 'no 
net loss' (Bull \& Brownlie 2015), there is variability in the policy characteristics to achieve this (Mckenney \& Kiesecker 2010).

Scientific evidence cautions that offsets must be designed carefully, or they can fall short of delivering their environmental objectives (Dickie et al. 2013; Temple et al. 2012; ICMM IUCN, 2012; Quétier et al. 2014; Treweek et al. 2009). Therefore, ecological feasibility should be the key consideration in offset policy design. Once ecological feasibility is established, it is possible that flexibility will remain in how an offset is designed. The economic and social aspects of design can then be considered. A better understanding of community acceptance could help to set the social boundaries within which offset policies operate, reducing the risk of public resistance to the practice (Burton et al. 2016; Richert et al. 2015).

Research on offsets to date has primarily focussed on their physical design (e.g. Dickie et al. 2013; Department of Environment and Conservation NSW 2011; Quétier \& Lavorel 2011; Madsen et al. 2010; Middle \& Middle 2010; Hayes \& Morrison-Sanders 2007). There is some work on social acceptability: Bougherara et al. (2013) study community acceptance of firms making versus buying offsets in milk production in France. Burton et al. (2016) quantify preferences of the West Australian community for biodiversity offsets, in the context of an oil and gas development impacting on the habitat of a species of a nationally protected migratory shorebird. Paredes (2015) conducted a similar study in Queensland.

In Australia, offsets are governed by both State and Commonwealth policies. Offsets are required when a development cannot avoid or mitigate all environmental impacts. The offset policies aim to achieve equivalence: a proponent must demonstrate that the offset will achieve 'no net loss', typically by protecting or improving equivalent environmental matter elsewhere. State offset policies apply to any residual environmental damage that occurs as a result of development within the state (e.g. Government of Western Australia 2011); the Commonwealth's Environmental Protection and Biodiversity Conservation (EPBC) Act Offset Policy applies in addition when a 'matter of national environmental significance' is affected by the development (Australian Government 2012). Australian policies, particularly the latter, are prescriptive in terms of permissible offset design: there is a strong emphasis on direct (like-for-like) actions and limited scope to substitute protection for other species, habitats or locations.

Using a discrete choice experiment (DCE) (Hensher et al. 2005), we relax the existing policy setting to investigate the social acceptability of changes in the design of a biodiversity offset for shorebirds. We examined preferences of the Australian community for the type of offset activity, location of the offset, the species and the number of individuals of that species protected, and the party responsible for implementing the offset. Overall economic and environmental tradeoffs were also examined by altering the number of jobs created, where it was hypothesised that more jobs would lead to greater acceptance of an offset.

In the DCE that follows, the hypothetical scenario controls for uncertainty related to the offset. The environmental damages are assumed to be known, and the policy options offered are assumed to deliver the required offset. We acknowledge that there is often uncertainty in these measurements in real offset applications, and the results of this study should be viewed with this in mind.

\section{Methods}

Discrete choice experiment 
Discrete choice experiments have been widely applied in the environmental non-market valuation literature to quantify the tradeoffs people are willing to make between different environmental attributes (Adamowicz 2004). A sequence of hypothetical questions (choice scenarios) to respondents, each of which contains potential policy options (alternatives), which in turn include statements of the outcomes of those policies. The outcomes are described in terms of the policy's characteristics (attributes). The set of attributes are the same for each alternative in the choice scenario, but they can take on different levels or amounts, varying the outcome of each alternative. Respondents are asked to select their most preferred policy package out of the set of alternatives given. An 'opt-out' is commonly included in the choice scenario so that a respondent is not forced to choose a policy alternative they would not vote for.

In this DCE, the hypothetical policy context was an oil and gas development in the vicinity of a beach on the Kimberley coast in Australia's north-west. Respondents were advised that some environmental impacts could be avoided or mitigated, but there would be residual impacts on the use of the beach as a feeding ground by 1000 Ruddy Turnstones (Arenaria interpres), a species of shorebird. These birds are protected under Australia's EPBC Act as a migratory species, and would require an offset to compensate for the impact if the development were to proceed (Australian Government 2012).

Developments in the resource sector commonly require offsets to manage residual impacts, and the migratory status of shorebirds triggers both State and Commonwealth policies, while having crossborder and international relevance. Hence our experimental context reflects current conditions for offset policy in Australia.

\section{Attribute selection}

The choice scenarios used attributes that varied the way in which an offset was implemented. Respondents were informed that each offset would achieve no net loss from an ecological perspective, to remove any uncertainty around the success of each option presented. Attributes were selected based on: (1) the policy characteristics currently used, or being considered, in Australian offset design (based on personal discussions); (2) the policy characteristics that were raised in two focus groups (16 participants); and, (3) information gathered from Burton et al. (2016). They included the proportion of direct offsets, location of the offset, who would implement the offset, what species and how many individuals would be protected, and the size of the development (Table 1). An 'opt-out of development' option was also specified. This avoids respondents being forced to make choices between offset packages when they would prefer the development not to proceed.

[Insert Table 1 around here]

In Australia, most offset policies prescribe that the majority of an offset should be direct; that is, a tangible on-ground intervention aimed at improving the environment of the impacted species (Middle \& Middle 2010). However, the potential to use other compensatory measures, or 'indirect offsets', also exists, where it can be demonstrated they will provide greater environmental benefit than a direct offset (Australian Government 2012; Government of Western Australia 2011). Indirect offsets relate to activities that aim to improve future management of the impacted species (Middle \& Middle 2010). For example, the EPBC Act Offset Policy permits indirect offsets where there is scientific uncertainty regarding the best approach for a direct offset, and research to improve understanding of the relevant ecosystem to guide future management is preferable. Approval of an offset under the policy means that there is a legal obligation to deliver the outcome of 'no net loss', 
whether that be via direct or indirect activity. Uncertainty in delivering the outcome (directly or indirectly) can be addressed by adjusting the quantity of the activity. However, even with these controls in place, it is possible that people could perceive direct offsets as being more reliable, or otherwise preferable. The proportion of direct offsets varied between 50 and $100 \%$, with indirect offsets defined as research that would improve existing on-ground management of the birds. In reality, it can be difficult to measure the environmental gains of indirect offsets in comparable metrics to direct offsets. For example, indirect offsets might be measured in research outputs or peer reviewed articles, compared to direct offsets being measured by habitat area, survival rates, or species diversity (Gonçalves et al. 2015; Australian Government 2012). Our experiment controlled for this by informing respondents that the ecological outcome was equivalent and achievable by either (or a combination of) a direct or indirect offset, confirmed by independent scientists, and measured in terms of the number of birds protected by the offset.

For a migratory shorebird species, it is possible to intervene at various points in its flyway to improve its welfare (Bamford et al. 2008). An intervention located away from the development site might not affect the welfare of the specific individuals impacted by the development, but it could ensure no net loss to the species overall. Many shorebirds stop to rest and feed at bottleneck sites in eastern Asia during their migration along the East-Asian-Australasian flyway (Iwamura et al. 2013). Conservation gains could be achieved outside of Australia, even if the development impact occurs within Australia (Gonçalves et al. 2015). Shorebird offsets in other regions might be cheaper and more effective if targeting critical habitat bottlenecks. However, issues of governance and a desire for local solutions to local problems may lead respondents to reject offsets away from the impact site. The offset location attribute reflected regions the shorebirds travel through: Western Australia, Northern Territory, New Zealand and China. As with the other attributes, respondents were told that each location was ecologically capable of delivering the offset. That is, the ecological effectiveness of location was held constant so that we could establish the trade-off required for a location away from the impact site to be socially acceptable: how many more birds are required to be protected, or how much more effective does the offset need to be, if it is located elsewhere.

While the financial obligation for an offset lies with the developer, they do not necessarily have to implement the offset themselves. We included an attribute to reflect this, where the implementer could be the developer, the Government's environment department for the region in which the offset occurs, or a third party company with a proven track record in offsets. It was anticipated that respondents might have less confidence, for example, in the developer implementing the offset (Bull \& Brownlie 2015), relative to an independent third party. We did not vary the party responsible for regulating the offset, as the obligation to ensure its success lies with the Australian and West Australian governments.

Offsets are typically aimed at protecting the species impacted by a development, adhering to the strict definition of 'no net loss'; in this case, the Ruddy Turnstone. However, the community might perceive there to be greater benefits by protecting a more endangered species with the offset: the Eastern Curlew (Numenius madagascariensis). Including this alternative offers an initial response to the question posited by Bull and Brownlie $(2015$, p.5) as to "the extent to which loss of biodiversity is accepted in exchange for conservation of biodiversity of a higher priority". The Eastern Curlew has a similar migratory presence to the Ruddy Turnstone, making it a suitable substitute for the purpose of the experimental design. It was made clear to respondents that this species would be protected instead of (and not in combination with) the Ruddy Turnstone.

The number of individuals of the species protected by the offset was varied, so that potentially more birds would be protected relative to the number impacted by development. This allowed us to 
estimate how many additional birds would need to be protected for people to accept socially undesirable policy characteristics. The Ruddy Turnstone ranged from 1000 to 2000 individuals protected, and the Eastern Curlew from 500 to 2000. The difference in the minima reflected that at least 1000 turnstones had to be protected as that was the number impacted by development, while a smaller number of curlews might be acceptable given their more endangered status.

Finally, there was a split design, with two different survey versions: with either 500 or 1000 new jobs arising from the development. It was anticipated that the difference in economic size of the development would not change the preferences for the attributes of the offset, but may influence selection of the no development alternative.

\section{Survey and experimental design}

In the survey, respondents were introduced to the concept of biodiversity offsets and asked about their existing knowledge of them (see Supporting Information for sample characteristics). The steps required by developers to avoid, mitigate, then offset environmental damages to achieve 'no net loss' were described using an example of seagrass habitat. Next, respondents were presented with the hypothetical development and attribute descriptions, and the DCE. The choice scenarios were designed with three policy alternatives and an opt-out alternative. Ngene (Rose et al. 2012) was used to generate an s-efficient design using the parameters estimated in Burton et al. (2016) as priors (see Rose \& Scarpa 2008 for an overview of efficient designs), resulting in 24 choice scenarios blocked into four groups of six. Each respondent answered one block of six questions.

The DCE was accompanied by a consequential statement explaining the study results could be used to adapt current offset policy in Australia. Debriefing questions followed the choice experiment, asking respondents about the certainty of their answers and whether they found the choice scenarios or information provided confusing. Attribute non-attendance questions were not included due to the length of the survey. Another section asked respondents about their attitudes towards the oil and gas industry, including 15 questions aimed at measuring respondents' social license to operate (SLO) for the industry. A SLO is an implicit contract between an industry or company and its stakeholders, where the risk of socio-political challenges to the industry's operations is reduced if it behaves in a manner befitting its stakeholders' values (Prno \& Slocombe 2012; see Supporting Information). Finally, socio-demographic information was collected.

There was no personal cost included in this choice experiment. Conventionally, a cost is included to enable calculation of monetary values for changes in attributes. However, asking for a personal expenditure to achieve an offset that is a legal requirement (and the financial responsibility of the developer) was deemed inappropriate. This study was interested in the tradeoffs across attributes, rather than placing a dollar value on offset outcomes per se.

The survey was administered online by a market research company. A nationally representative sample (stratified by age, gender and location - see Supporting Information) of 1371 respondents completed the survey during October-November 2014. The survey was conducted in accordance with The University of Western Australia's Human Research Ethics procedures (\#RA/4/1/6036).

\section{Data analysis}

Data were analysed using Intercooled Stata/IC 13.1 (Statacorp 2013) (see Supporting Information for a description of random utility theory and the multinomial logit model, and Train 2009). We specified an error components multinomial logit model to account for different correlation patterns 
across alternatives, and in particular between the offset options compared to the opt-out (Scarpa et al. 2006). Individual specific covariates were interacted with the alternative specific constant (ASC) or with attribute variables. The ASC captures the utility associated with a labelled alternative, in this case the opt-out. The full utility function specification is reported in the Supporting Information. Note that alternative modelling approaches that capture additional heterogeneity exist, including mixed logit models with parameters treated as random (Train 2009). Several alternative models were estimated with this data, and while they did better explain the distribution of preferences across individuals in the sample, the results for an average individual were similar and did not alter the policy conclusions which are the focus of this paper.

\section{Results}

The greater the SLO granted to an industry by its stakeholders, the lower the risk to the industry's operations (Prno \& Slocombe 2012). In the case of the Australian oil and gas industry, the stakeholders are the general public, who could be directly or indirectly affected by the environmental impacts of an oil or gas development. Following the approach of Richert et al. (2015), two measures of the SLO for the industry were derived from the 15 questions: a measure of 'economic legitimacy' (SLO_Econ), which is attained when respondents believe the industry will provide economic benefits; and, a measure of 'social legitimacy' (SLO_SOC), which is reached when respondents believe the industry will improve community wellbeing and will act in consideration of community interests. These were derived as simple averages of scores from two subsets of questions. The partition into the two measures was confirmed by factor analysis: the Supporting Information provides further detail. In the current context, it was anticipated that a stronger social license would lead to increased acceptance of offsets, and of the developer implementing them.

Table 2 reports the choice model results which show that respondents preferred higher levels of direct offset relative to indirect (Percent), and that they had a preference for more Birds being protected by the offset. The effect of changing bird species is reflected in two coefficients: the impact of changing species on the marginal value of additional birds protected (Ruddy TurnstonexBirds), and a species specific dummy (Ruddy Turnstone). The former is negative, indicating that the marginal value of an additional Ruddy Turnstone being protected is less than that of an Eastern Curlew, but the species specific dummy is positive, suggesting that there is an initial preference for Ruddy Turnstone over Eastern Curlew. At the original level of 1000 birds affected, respondents were (statistically) indifferent between the two species, but as numbers increased, the marginal value gained from additional Ruddy Turnstones was less than that for Eastern Curlews, implying they valued the more endangered species more (see Supporting Information for a more detailed analysis).

[Insert Table 2 around here]

The preference ranking of offset location was Western Australia (where the impact occurred), Northern Territory, New Zealand and then China. We investigated whether there was an 'own state' preference by interacting the location variables with a dummy variable indicating whether the respondent was a West Australian resident (WA). West Australian residents gained greater disutility from shifting the offset out of the impact State compared to residents of other states. Unfortunately the sample of Northern Territory respondents was not large enough (reflecting the small size of the region: $1 \%$ of the national population) to estimate a model that would identify if Territory residents had greater preferences to bring the offset to the Northern Territory. 
On average, the Developer was less preferred as the implementer of the offset, and a 3rd party more preferred, relative to the Government. By interacting the developer variable with the SLO variables, we explored whether the level of SLO changes the acceptability of the developer to respondents. This was the case for the social legitimacy variable (SLO_Soc $x$ Developer), where the coefficient was positive and significant, but not for economic legitimacy (SLO_Econ $x$ Developer), which was negative but not significant.

Given the normalization of the SLO variables (zero mean and a standard deviation of one), respondents who had a social legitimacy score one standard deviation from the mean would have an implied marginal utility for the developer being the implementer of +0.02 (from Table 2, the coefficient for Developer plus that for SLO_Soc x Developer, i.e.: -0.189+0.211). That is, this group of the sample were essentially indifferent between the government and the developer implementing the offset. Conversely, those who held a lower social legitimacy score would be even more averse to an offset implemented by the developer. A relatively small proportion of the sample preferred the developer over the government (those at the upper end of the distribution of the social legitimacy score). However, this effect is not sufficient to overcome the preference for the $3^{\text {rd }}$ party implementer.

Respondents could potentially reject the offsets offered by selecting the opt-out, which would retain the original ecological conditions, but also no economic benefit in terms of jobs. However, relatively few did: in only $13 \%$ of choice occasions was the opt-out selected.

By interacting the ASC dummy with the SLO variables, one can identify whether the level of SLO changes the tendency to reject development entirely. Individuals who held higher social license scores (as shown by coefficients on SLO_Econ $x$ ASC, SLO_SOC $x$ ASC) tended to hold a lower utility for the opt-out; or conversely, those who held a low SLO for the oil and gas industry tended to select the opt-out option more often.

We introduced the number of jobs as an interaction variable with the opt-out ASC to allow for the possibility that the probability of rejecting the development entirely may be influenced by its economic impact, but it was not significant (results not reported here).

Tradeoffs across attributes can be estimated through marginal rates of substitution; that is, the rate at which one can substitute the level of one attribute for another, and leave the respondent at the same level of utility. These are calculated by dividing the marginal utility of an attribute by that of the numeraire, which can be any continuous attribute. In this case, we used the number of Ruddy Turnstones. The interpretation of the resulting marginal rates of substitution is the change in the number of Ruddy Turnstones protected that is required to exactly compensate for a change in another attribute. A negative number indicates a change in an attribute that respondents value (i.e. bird numbers can be reduced), while a positive number implies that the attribute change reduces utility, and more birds are needed to compensate for it.

[Insert Table 3 around here]

Table 3 reports the marginal rates of substitution for the attributes measured in terms of numbers of Ruddy Turnstones. If the Eastern Curlew were to be used as the numeraire the numbers would be $61 \%$ of those in Table 3, due to the higher marginal value placed on the species. We caution that while precise estimates of bird numbers are presented here, in practise there will be scientific uncertainties around how many birds an offset will actually generate. The numbers here are intended to be indicative of the magnitude of the offset required. 
For offset location, if the default is 1000 Ruddy Turnstones in an offset in Western Australia, an additional 353 birds would have to be included to compensate for moving the offset to the Northern Territory, 808 for New Zealand, and 2092 to compensate the movement to China (i.e. the offset in China would require a total of 3092 birds to be seen as equivalent to the 1000 birds in Western Australia). For a resident in Western Australia, these values were higher: the offset in China would require a total of 6752 birds to compensate (i.e. from Table 3: default[1000] + China[2092] + WA x China[3660]).

For direct versus indirect offsets, eight fewer birds would be required for every additional percentage point of direct offset. That is, an increase from $90 \%$ to $95 \%$ would require 40 fewer birds; a decrease from $90 \%$ to $85 \%$ would require 40 additional birds to be considered equivalent.

Table 3 also shows that a change in implementer from government to the developer would require an additional 352 birds in the offset for a respondent with mean SLO scores. Individuals with a social legitimacy score that is one standard deviation above the mean would prefer the developer to undertake the offset, and in fact would be content with a slightly smaller number of birds protected $(352-393=-41)$. Although reported, note that the effect that economic legitimacy has on the developer is not significantly different from zero. Acceptance of the use of a third party implementer would be feasible with a lower number of birds protected, relative to government implementation.

\section{Discussion}

With biodiversity offsets being increasingly used worldwide to compensate for unavoidable environmental damages resulting from development, it is important for governments to set appropriate policies for offset implementation (Gonçalves et al. 2015). Getting the science right is obviously critical in meeting the objective of 'no net loss'; however, there might be different methods by which that could be achieved. It is important to ensure that offset policies reflect what is acceptable by community standards. This study explored the community's acceptance of a number of potential policy characteristics, in the context of Australian biodiversity offsets for migratory shorebirds impacted by an oil and gas development. Being a new area of study, it is important to note that the extrapolation of these results to other biodiversity contexts or to policy settings outside of Australia must be viewed with caution.

There was widespread acceptance of the use of offsets in this context, with respondents rarely opting out of development. We had anticipated that a development leading to more jobs created (and corresponding economic benefit to the community), would influence the willingness to allow the project to proceed. For the number of jobs we considered, this was not the case, implying that the scale of the development was not influencing attitudes towards environmental management.

The social license to operate that individuals held for the oil and gas industry influenced the general acceptance of offsetting: those who granted a lower SLO were more averse to the development proceeding, relative to those granting a higher SLO. From a developer's perspective, this would suggest that maintaining a positive relationship with the local community will be important for gaining approval to embark on projects requiring offsets (Richert et al. 2015).

There was a preference for more shorebirds to be protected by the offset, and, once the number of birds exceeded the number impacted (1000 birds), the marginal value for each additional bird was greater for the more endangered Eastern Curlew relative to the impacted Ruddy Turnstone. This suggests that 'trading-up' of species was accepted by the community. Currently in Australia, the Commonwealth legislation does not allow this substitution (Australian Government 2012); however, 
some State policies suggest it could be possible if the ecological benefit to the substitute species exceeded that of an offset for the impacted species (Government of Western Australia 2011). If the science supports an offset focusing on a more critically endangered species (or habitat), it would be worthwhile having flexibility in offset policies to allow this.

There was a preference for direct versus indirect offsets, suggesting respondents may have been placing a risk premium on indirect offsets to account for uncertainty in research outcomes, despite being told the offset was equivalent via either approach. However, there is also literature which shows that people may care about how policy is implemented, and not just the outcome (Rogers 2013). This finding supports the current Australian position for the majority of an offset to be direct (Australian Government 2012). However, the use of indirect offsets could be compensated for by other factors: increasing the number of shorebirds protected by the offset beyond the number impacted (an additional eight Ruddy Turnstones for every percentage point) was an acceptable tradeoff for increasing the proportion of indirect offset activity. This suggests that where direct offsets may not be practicable, indirect offsets can be considered on the condition that they are ecologically plausible and that some multiplier is used to protect more of the impacted matter (i.e. over and above any multiplier required to improve confidence levels in biodiversity outcomes, see Bull \& Brownlie 2015).

As in Burton et al. (2016), respondents preferred the offset to be located close to the site of impact (Western Australia). Utility diminished as the offset moved offshore: China was the least preferred location. Burton et al. (2016) only sampled population from Western Australia, meaning it was not possible to differentiate between an ecological imperative (keeping the offset near the impact) and a geo-social one (keeping the offset in the same state as the respondent). Here, the national sample demonstrated that the effect of diminishing utility with increased distance from the impact site was present, irrespective of which state they lived in. This implies that, for the Australian locations where perceived ecological and governance risks should be constant, there is a preference to keep the offset close to the impact site due to geographical distance. However, for international locations, the diminished utility could additionally reflect concerns about ecological and governance risks: for example, the ability of the Australian Government to enforce an outcome. While respondents were informed that the ecological outcome was equivalent at all locations, they may not have accepted this due to their own perceptions of risk, or a preference for locations independent of ecological outcomes. This reaction to location was emphasised if the respondent was a West Australian resident, suggesting there may also be some degree of 'local offsets for local people' (e.g. reflecting enhanced use value or a desire to keep the benefits within their State).

It was possible to compensate for the disutility of moving the offset away from the impact site by increasing the number of birds protected. A substantial increase in the number of birds was required, especially if the offset was located overseas (thousands of birds). From a community perspective, offsets are unlikely to be acceptable if they are too distant from the impact site. This is an interesting divergence from an ecological perspective: in the case of migratory shorebirds it would be desirable to use offsets internationally at sites with habitat bottlenecks (Iwamura et al. 2013). Policy design will need to be mindful of these potentially conflicting views, and should consider raising community awareness if international offset strategies are adopted.

Respondents were more accepting of an offset if it was implemented by the government (i.e. the relevant environmental department for the region), relative to the developer themselves. A third party with a proven track record in offsetting was the most preferred implementer. Individuals who held a high SLO, granting the oil and gas industry social legitimacy, would accept the developer as an implementer. This was a very small proportion of individuals, as social legitimacy is difficult for the 
industry to achieve (Richert et al. 2015). While economic legitimacy is more readily granted to the oil and gas industry, it did not improve the acceptability of the developer as an implementer. This implies that, even when a developer has a generally positive economic legitimacy, the majority would still prefer that an offset policy requires implementation via the transferring of funds from the developer to the government or a third party. We reiterate that preferences for who implements the offset were set in the context of Australian governments being responsible for monitoring the offset, and that trust in the monitoring body could influence preferences (an issue we did not explore). Currently, Australian policies are not prescriptive as to who should implement an offset.

In conclusion, the choice experiment has shown a general acceptance of biodiversity offsets by the Australian community in the context of an oil and gas development. It also provides support for increasing the flexibility in some offset policy characteristics. In particular, the trading up of species was considered acceptable. Other policy characteristics would be accepted provided that appropriate compensation was offered by protecting more biodiversity. This was relevant for increasing the proportion of indirect offset activity and moving the offset to a location away from the impact site. Acceptability of offsetting improved if the responsibility of implementation was shifted away from the development company and to a third party.

\section{Supporting Information}

'Measuring Social License to Operate' (Appendix S1), 'Estimation of discrete choice models' (Appendix S2), 'Sample characteristics' (Appendix S3), and 'Marginal value of bird species' (Appendix S4) are available online. The authors are solely responsible for the content and functionality of these materials. Queries (other than absence of the material) should be directed to the corresponding author.

\section{Literature Cited}

Adamowicz WL. 2004. What's it worth? An examination of historical trends and future directions in environmental valuation. The Australian Journal of Agricultural and Resource Economics 48(3): 419443.

Australian Government. 2012. Environment Protection and Biodiversity Conservation Act 1999 Environmental Offsets Policy. Commonwealth of Australia, Canberra.

Bamford M, Watkins D, Bancroft W, Tischler G, Wahl J. 2008. Migratory shorebirds of the East AsianAustralasian flyway: population estimates and internationally important sites. Wetlands International, Oceania, Canberra.

Bougherara D, Costs S, Teisl M. 2013. Making or buying environmental public goods: do consumers care? Land Economics 89(4): 767-781.

Boutilier RG, Thomson I. 2011. Modelling and Measuring the Social License to Operate: fruits of a dialogue between theory and practice. Available from:

http://socialicense.com/publications/Modelling\%20and\%20Measuring\%20the\%20SLO.pdf (accessed 23/08/2014).

Bull JW, Brownlie S. 2015. The transition from No Net Loss to a Net Gain of biodiversity is far from trivial. Oryx DOI: 10.1017/S0030605315000861. 
Burton M, Rogers A, Richert C. 2016. Community acceptance of biodiversity offsets: evidence from a choice experiment. Australian Journal of Agricultural and Resource Economics DOI: 10.1111/14678489.12151.

Department of Environment and Conservation NSW. 2011. Avoiding and offsetting biodiversity loss: case studies. Department of Environment and Conservation New South Wales, Sydney.

Dickie I, McAleese L, Pearce B, Treweek J. 2013. Marine Biodiversity Offsetting - UK Scoping Study. The Crown Estate, London.

Gonçalves B, Margues A, Soares AMVDM, Pereira HM. 2015. Biodiversity offsets: from current challenges to harmonized metrics. Current Opinion in Environmental Sustainability 14: 61-67.

Government of Western Australia. 2011. WA Environmental Offset Policy. The Government of Western Australia, Perth.

Hayes N, Morrison-Saunders A. 2007. Effectiveness of environmental offsets in environmental impact assessment: practitioner perspectives from Western Australia. Impact Assessment and Project Appraisal 25(3): 209-218.

Hensher D, Rose J, Greene W. 2005. Applied choice analysis: a primer. Cambridge University Press, Cambridge.

ICMM IUCN. 2012. Independent report on biodiversity offsets. Prepared by The Biodiversity Consultancy. Available from: http://www.icmm.com/biodiversity-offsets (accessed 06/04/2015).

Iwamura T, Possingham HP, Chadès I, Minton C, Murray NJ, Rogers DI, Treml EA, Fuller RA. 2013. Migratory connectivity magnifies the consequences of habitat loss from sea-level rise for shorebird populations. Proceedings of the Royal Society B DOI: 10.1098/rspb.2013.0325McKenney B, Kiesecker J. 2010. Policy Development for Biodiversity Offsets: A Review of Offset Frameworks. Environmental Management 45(1): 165-176.

Middle G, Middle I. 2010. A review of the use of environmental offset as a policy mechanism in the environmental impact assessment process (EIA) in Western Australia. Impact Assessment and Project Appraisal 28(4): 313-322.

Paredes SJ. 2015. The role of offsets in compensation for damage in the coastal and marine environments. Masters thesis, Queensland University of Technology, Brisbane. Available from: http://eprints.qut.edu.au/86512/ (accessed 11/05/2016)

Prno J, Slocombe DS. 2012. Exploring the origins of 'social license to operate' in the mining sector: Perspectives from governance and sustainability theories. Resources Policy 37: 346-357.

Quétier F, Lavorel S. 2011. Assessing ecological equivalence in biodiversity offset schemes: Key issues and solutions. Biological Conservation 144: 2991-2999.

Quétier F, Regnery B, Lavorel S. 2014. No net loss of biodiversity of paper offsets: A critical review of the French no net loss policy. Environmental Science and Policy 38: 120-131.

Richert C, Rogers A, Burton M. 2015. Measuring the extent of a social license to Operate: The influence of marine biodiversity offsets in the oil and gas sector in Western Australia. Resources Policy 43: 121-129. 
Rogers, AA, 2013. Social Welfare and Marine Reserves: Is Willingness to Pay for Conservation Dependent on Management Process? A Discrete Choice Experiment of the Ningaloo Marine Park in Australia. Canadian Journal of Agricultural Economics 61(2): 217-238.

Rose J, Collins A, Bliemer M, Hensher D. 2012. Ngene 1.1.1. Statistical Software.

Scarpa R, Ferrini S, Willis KG. 2006. Performance of error component models for status-quo effects in choice experiments. Pages 247-274 in Scarpa R, Alberini A, editors. Applications of simulation methods in environmental and resource economics. Springer, Netherlands.

Scarpa R, Rose JM. 2008. Design efficiency for non-market valuation with choice modelling: how to measure it, what to report and why. The Australian Journal of Agricultural and Resource Economics 52: $253-282$.

Statacorp 2013, Stata/IC 13.1, Statistical Software.

Temple HJ, Anstee S, Ekstrom J, Pilgrim JD, Rabenantoandro J, Ramanamanjato JB, Randriatafika F, Vincelette M. 2012. Forecasting the path towards a Net Positive Impact on biodiversity for Rio Tinto QMM. IUCN, Gland, Switzerland.

ten Kate K, Bishop J, Bayon R. 2004. Biodiversity offsets: Views, experience, and the business case. IUCN: Gland, Switzerland and Cambridge, UK and Insight Investment, London, UK.

Train K. 2009. Discrete Choice Methods with Simulation. Second edition. Cambridge University Press, New York.

Treweek J, ten Kate K, Butcher B, Venn O, Garland L, Moran D, Thompson S. 2009. Scoping Study for the Design and Use of Biodiversity Offsets in an English Context. Treweek Environmental Consultants, Final report to Department for Environment, Food and Rural Affairs, London. 
Table 1. The offset policy attributes included in the choice experiment, with level specifications and variable names.

\begin{tabular}{|c|c|c|c|}
\hline Attribute & Level & Variable name & (and coding) \\
\hline $\begin{array}{l}\text { Proportion of direct } \\
\text { offset activity }\end{array}$ & $\begin{array}{l}50 \%, 60 \%, 70 \%, 80 \%, \\
90 \%, 100 \%\end{array}$ & Percent & (continuous) \\
\hline Location of offset & $\begin{array}{l}\text { Western Australia } \\
\text { Northern Territory } \\
\text { New Zealand } \\
\text { China }\end{array}$ & $\begin{array}{l}\text { Western Australia } \\
\text { Northern Territory } \\
\text { New Zealand } \\
\text { China }\end{array}$ & $\begin{array}{l}\text { (base level) } \\
\text { (= } 1 \text { if present, } 0 \text { otherwise) } \\
\text { (= } 1 \text { if present, } 0 \text { otherwise) } \\
\text { (= } 1 \text { if present, } 0 \text { otherwise) }\end{array}$ \\
\hline Offset implementer & $\begin{array}{l}\text { Government } \\
\text { Developer } \\
\text { Third Party }\end{array}$ & $\begin{array}{l}\text { Government } \\
\text { Developer } \\
3^{\text {rd }} \text { Party }\end{array}$ & $\begin{array}{l}\text { (base level) } \\
\text { (= } 1 \text { if present, } 0 \text { otherwise) } \\
\text { (= } 1 \text { if present, } 0 \text { otherwise) }\end{array}$ \\
\hline $\begin{array}{l}\text { Species protected by } \\
\text { offset }\end{array}$ & $\begin{array}{l}\text { Eastern Curlew } \\
\text { Ruddy Turnstone }\end{array}$ & $\begin{array}{l}\text { Eastern Curlew } \\
\text { Ruddy Turnstone }\end{array}$ & $\begin{array}{l}\text { (base level) } \\
\text { (= } 1 \text { if present, } 0 \text { otherwise) }\end{array}$ \\
\hline $\begin{array}{l}\text { Number of birds } \\
\text { protected }\end{array}$ & $500^{*}, 1000,1500,2000$ & Birds & (continuous) \\
\hline
\end{tabular}


Table 2. Estimates of an error components logit model for the choice data.

\begin{tabular}{|c|c|c|c|}
\hline Variable & Coefficient & (SE) & \\
\hline Percent & 0.004 & $(0.001)$ & $* * *$ \\
\hline Ruddy Turnstone & 0.282 & (0.105) & $* * *$ \\
\hline Birds & 8.7E-4 & $(3.8 \mathrm{E}-5)$ & $* * *$ \\
\hline Ruddy TurnstonexBirds & $-3.3 \mathrm{E}-4$ & $(6.9 E-5)$ & $* * *$ \\
\hline Northern Territory & -0.190 & $(0.037)$ & $* * *$ \\
\hline WAxxNorthern Territory & -0.490 & $(0.126)$ & $* * *$ \\
\hline New Zealand & -0.435 & $(0.054)$ & $* * *$ \\
\hline WAxNew Zealand & -0.623 & $(0.184)$ & $* * *$ \\
\hline China & -1.127 & $(0.056)$ & $* * *$ \\
\hline WAxChina & -0.845 & $(0.185)$ & $* * *$ \\
\hline Developer & -0.189 & $(0.032)$ & $* * *$ \\
\hline SLO_Econ x Developer & -0.054 & $(0.036)$ & \\
\hline SLO_Soc x Developer & 0.211 & $(0.035)$ & $* * *$ \\
\hline $3^{\text {rd }}$ Party & 0.101 & $(0.030)$ & $* * *$ \\
\hline SLO_Econ x ASC & -1.107 & (0.171) & $* * *$ \\
\hline SLO_Soc x ASC & -0.930 & $(0.160)$ & $* * *$ \\
\hline ASC & -2.839 & $(0.240)$ & $* * *$ \\
\hline$\sigma^{2}$ & 3.776 & (0.198) & $* * *$ \\
\hline
\end{tabular}

Notes: $* * *$ denotes significance at the $99 \%$ level of confidence.

Log likelihood = -9199.591; number of choice occasions = 8226; number of individuals $=1371$.

Interaction variable definitions:

SLO_Econ: social license to operate economic legitimacy variable, normalised so mean=0, std dev. $=1$

SLO_Soc: social license to operate social legitimacy variable, normalised so mean=0, std dev. =1

WA: dummy variable $=1$ if respondent lives in Western Australia

Percent and Birds are continuous variables

Ruddy Turnstone, Northern Territory, New Zealand, China, Developer, and $3^{\text {rd }}$ party $=1$ if present; $=0$ otherwise. 
Table 3. Marginal rates of substitution, using the number of Ruddy Turnstones as the numeraire.

\begin{tabular}{llll} 
Variable & Coefficient & \multicolumn{2}{c}{$95 \% \mathrm{Cl}$} \\
\hline percent & -8 & -12 & -5 \\
Northern Territory & 353 & 206 & 500 \\
WA x Northern Territory & 1263 & 750 & 1776 \\
New Zealand & 808 & 554 & 1061 \\
WA x New Zealand & 1965 & 1197 & 2732 \\
China & 2092 & 163 & 2521 \\
WA x China & 3660 & 2676 & 4645 \\
Developer & 352 & 204 & 499 \\
SLO_Econ x Developer & 100 & -33 & 233 \\
SLO_Soc x Developer & -393 & -548 & -238 \\
$3^{\text {rd }}$ party & -188 & -301 & -75 \\
\end{tabular}

Notes: For the location variables, these represent the marginal rates of substitution for respondents who live in WA, and those not in WA.

For the SLO interactions, these represent the change in marginal rates of substitution as the SLO changes by one, equivalent to one standard deviation. 